\title{
Structural, Optical \& Surface Morphology of Zinc Oxide (ZnO) Nanorods in Molten Solution
}

\author{
Dr. Mahendra Kumar ${ }^{*}$ and Ankit Gupta \\ University Of Lucknow, Lucknow 226007, India
}

\begin{abstract}
ZnO}$ (Zinc oxide) nanorods have been developed by using molten solution using the spin coating technique at low temperature. Zinc acetate dehydrate, Zinc nitrate hexahydrate and hexamethylenetetramine (HMT) were used as a base material. The $\mathrm{ZnO}$ seed layer was first deposited by spin coated of ethanol zinc acetate dehydrate $\left[\mathrm{Zn}(\mathrm{CH} 3 \mathrm{COO}) 2.2 \mathrm{H}_{2} \mathrm{O}\right]$ solution on a glass substrate (RI 1.522). $\mathrm{ZnO}$ nanorods were grown on the $\mathrm{ZnO}$ seed layer from zinc nitrate hexahydrate and hexamethylenetetramine solution, and their diameters, lengths were controlled by precursor solution concentration and film developing time. Optical study was done with the help of UV-Vis-NIR V670JASCO spectrophotometer. Structural properties showed the highly oriented nature of $\mathrm{ZnO}$ nanorods. The FESEM (Field emission scanning electron microscope) was used to measure diameter of $\mathrm{ZnO}$ nanorods.
\end{abstract}

Key words: XRD (X-ray diffraction), zinc oxide, nanorods, FESEM (Field emission scanning electron microscope).

\section{Introduction}

$\mathrm{ZnO}$ is extensively used in the development of optoelectronic devices due to its versatile properties, such as a direct bad gap of $3.37 \mathrm{eV}$, a high exciton binding energy of $60 \mathrm{MeV}$, an optical grain of $300 \mathrm{~cm}^{-1}$ and high mechanical and thermal stability. The controlled morphology, growth parameters and physical properties of these structures are being intensely discussed by many researchers. So many efforts have been made to control the morphology and methods to achieve better alignment and well-controlled morphology of $\mathrm{ZnO}$ nanostructures [1].

$\mathrm{ZnO}$ has been widely used in few applications such as in catalysis, solar cells, short-wavelength LED's (Light-emitting devices), transparent conductors, chemical sensors, and piezoelectric nanomaterials [2]. The use of well-aligned $\mathrm{ZnO}$ nanorods in the development of a UV laser has strongly motivated researchers to study the alignment of $\mathrm{ZnO}$ nanostructures, such as nanorods, because the controlled morphology has a significant effect on the working performance of the nanoscale-based

\footnotetext{
*Corresponding author: Mahendra Kumar, assistant professor.
}

optoelectronics devices.

An XRD (X-ray diffraction) analysis has indicated the orientation of the nanorods perpendicular to the substrate by exhibiting only the characteristic diffraction peaks for the patterned arrays of the $\mathrm{ZnO}$ nanorods [3]. In this work $\mathrm{ZnO}$ nanorods have been produced by using the solution, zinc acetate dehydrate in ethanol as a seed layer. The growth of $\mathrm{ZnO}$ nanorods, diameter and length are controlled by changing the solution concentration and immersion time in equimolar of zinc nitrate hexahydrate and hexamethylenetetramine (HMTA) in deionized water at a $90{ }^{\circ} \mathrm{C}$ and their morphologies, preferential orientation and optical properties were examined [4].

\section{Results and Discussion}

\subsection{Optical Properties of ZnO Nanorods}

Fig. 1 shows the optical transmittance spectrum of nanocrystalline $\mathrm{ZnO}$ nanorods at $90{ }^{\circ} \mathrm{C}$ for precursor concentration $35 \mathrm{~mm}$ from immersion time 180 minutes annealed at $450{ }^{\circ} \mathrm{C}$ for 30 minutes using UV-Visible region from $200 \mathrm{~nm}$ to $800 \mathrm{~nm}$. The transmittance is over $80 \%$ in the visible region from $400 \mathrm{~nm}$ to $800 \mathrm{~nm}$ for all the samples. Sharp absorption 


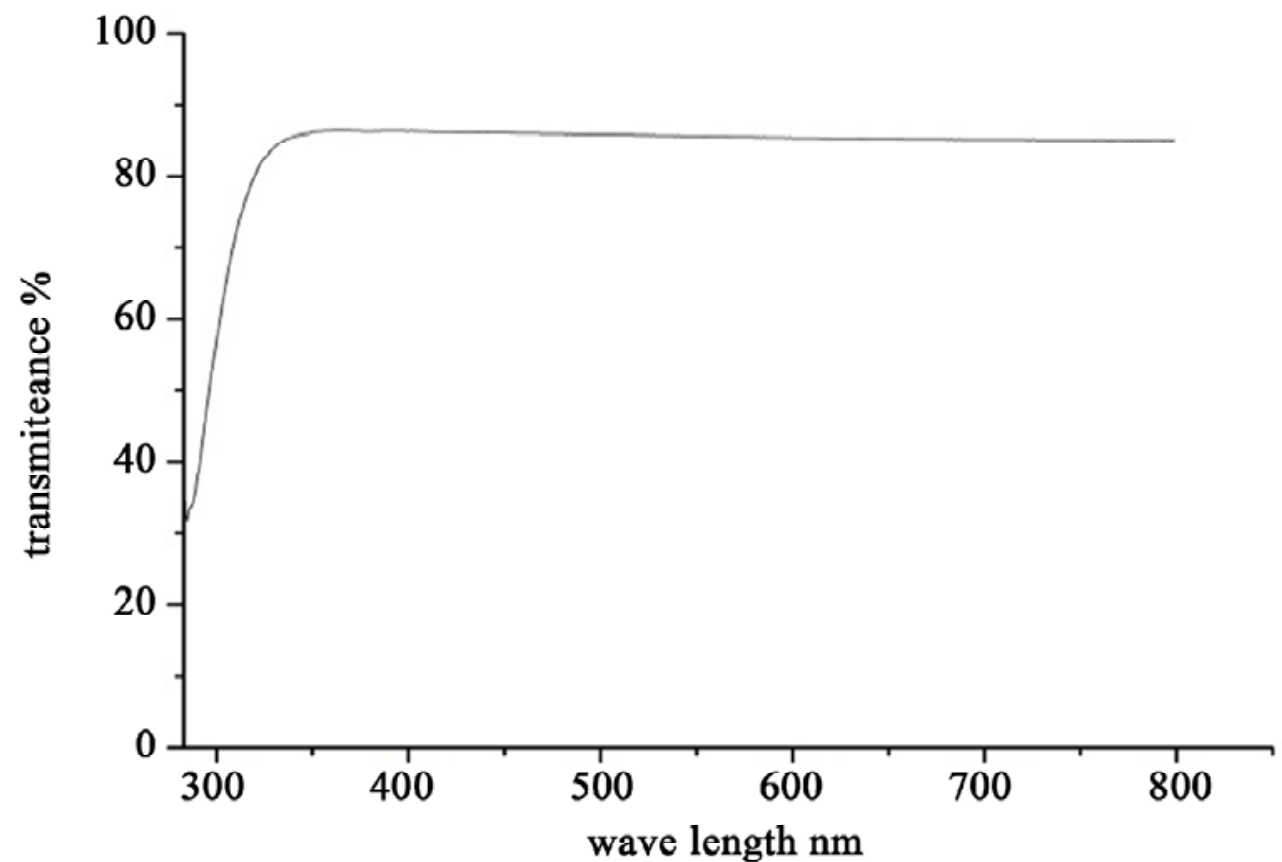

Fig. 1 The transmittance spectrum of $\mathrm{ZnO}$ nanorods at $90^{\circ} \mathrm{C}$ for precursor concentration $35 \mathrm{~mm}$ from immersion time 180 min.

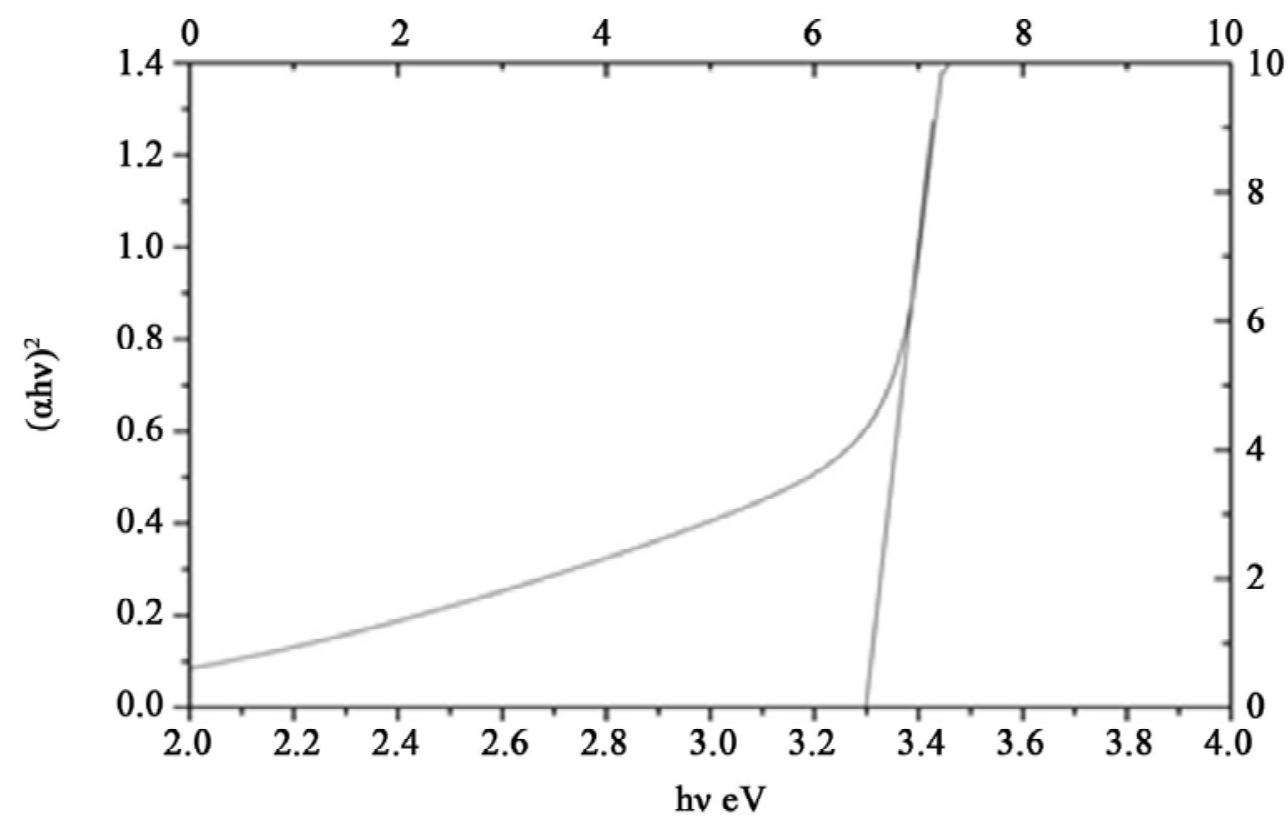

Fig. 2 Plot of $(\alpha h v)^{2}$ vs photon energy $h v$ of $\mathrm{ZnO}$ nanorods.

edge is located at $380 \mathrm{~nm}$ which is due to the fact that the $\mathrm{ZnO}$ is a direct ban gap semiconductor [5]. The corresponding optical band gap of $\mathrm{ZnO}$ thin film is estimated by extrapolation of the linear relationship between $(\alpha h v)^{2}$ and $h v$ according to Eq. (1):

$$
\alpha h v=\frac{\mathrm{A}(h v-\mathrm{Eg})}{2}
$$

where, $\alpha$ is the absorption coefficient, $h v$ is the photon energy, $E g$ is the optical band gap and $A$ is a constant.

Fig. 2 depicts the plot of $(\alpha h v)^{2}$ versus photon energy $h v$. The value of the direct optical band gap $E g$ is calculated from the intercept of $(\alpha h v)^{2}$ vs $h v$ curve had also been plotted. The presence of a single slop in 
the plot suggests that the $\mathrm{ZnO}$ nanorod has direct and allowed transition [6]. The band gap value of $\mathrm{ZnO}$ nanorod is found to be $3.3 \mathrm{eV}$ which is slightly smaller to /bulk $\mathrm{ZnO}(3.37 \mathrm{eV})$.

This difference is due to the fact the values of band gap $E g$ depend on many factors, e.g. the granular structure, the nature and concentration of precursors, the structural defects and the crystal structure of the films. Moreover, departures from stoichiometry form lattice defects and impurity stats. It has been reported that the band gap difference between the thin film and crystal is due to the grain boundaries and the imperfection of the polycrystalline thin films. It was reported that this band gap difference between the film and bulk $\mathrm{ZnO}$ is due to the grain boundary, the stress and the interaction potentials between defects and host materials in the films.

\subsection{Structural Analysis of $\mathrm{ZnO}$ Nanorods}

Fig. 3 depicts the XRD pattern of the crystal structure and orientation of the nanocrystalline $\mathrm{ZnO}$ nanorods deposited on glass substrate using spin coating at 2,000 rpm, pre-heated at $150{ }^{\circ} \mathrm{C}$ and annealed in air at $4500^{\circ} \mathrm{C}$. From the XRD pattern, one can clearly observe a diffraction peak at $2 \theta=34.426^{\circ}$.
Strong preferential growth is observed along $c$-axis, i.e. (002), suggesting that the prepared $\mathrm{ZnO}$ nanorods have the wurtizite structure.

The unit cell "a" and "c" of the crystalline $\mathrm{ZnO}$ nanorods with (002) orientation is calculated using the relation Eqs. (2) and (3):

$$
\begin{aligned}
& \mathrm{a}=\frac{1}{3 \sin \theta} \\
& \mathrm{c}=\lambda \cdot \sin \theta
\end{aligned}
$$

The values obtained for the unit cell $\mathrm{a}=3.007 \AA$ and $\mathrm{c}=5.21 \AA$ are calculated.

From the XRD spectrum, grain size $(D)$ of the film is calculated using debay scherrer formula.

$$
\mathrm{D}=\mathrm{k} \lambda \beta \cdot \cos \theta
$$

where, $\mathrm{k}$ is a constant to be taken $0.49, \lambda$ is the XRD wave length $(\lambda=1.5406 \AA$ ), $\beta$ is the FWHM (Full width at half maximum) and $\theta$ is the Bragg angle. By inserting the different values from Table 2 in the Scherrer formula grain size of (002) oriented thin film is $44.12 \mathrm{~nm}$ which is same as reported in literature.

The dislocation density $(\delta)$, which represents the amount of defects in the crystal, is estimated from the following equation:

$$
\delta=\frac{1}{\mathrm{D}^{2}}
$$

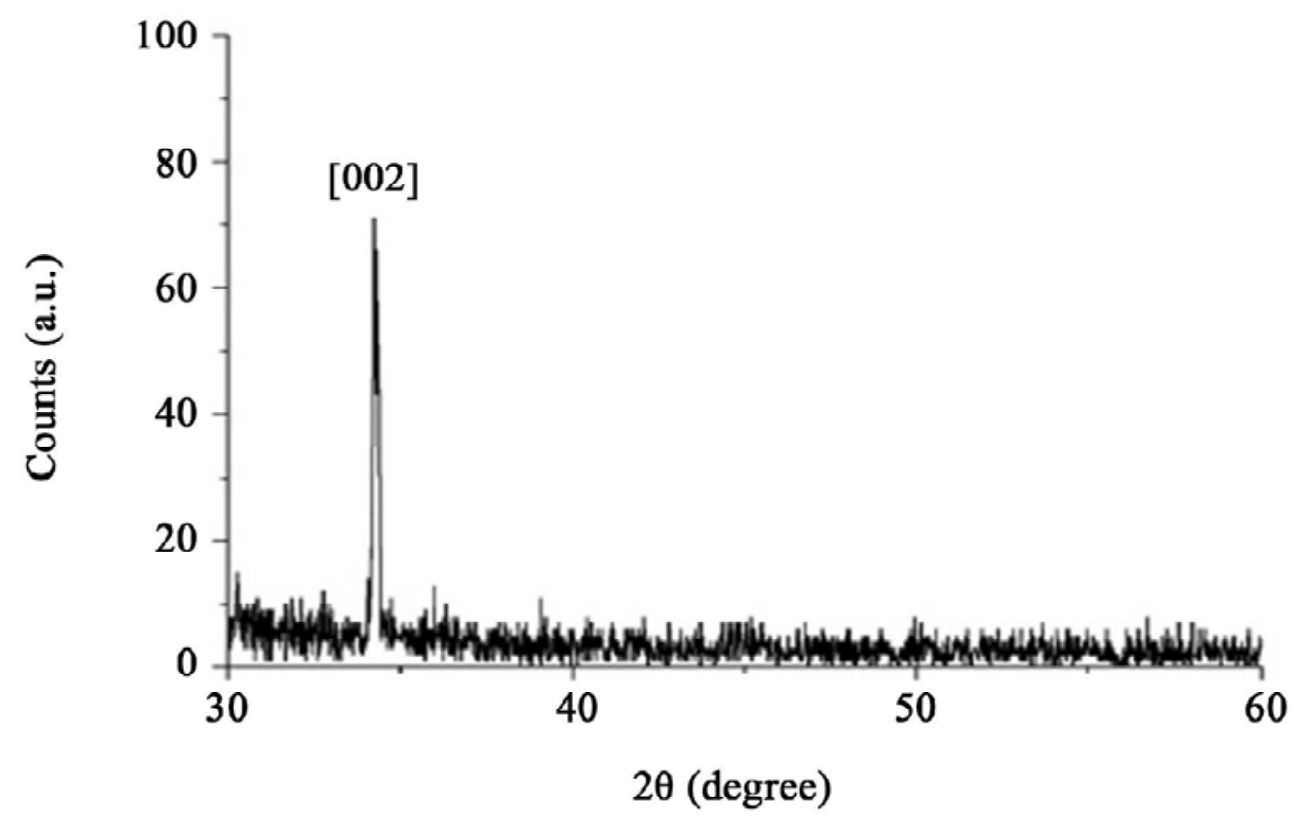

Fig. $3 \mathrm{X}$-Ray diffraction of the $\mathrm{ZnO}$ nanorods grown at $90{ }^{\circ} \mathrm{C}$ for $180 \mathrm{~min}$ from the $35 \mathrm{mM}$ precursor concentration. 


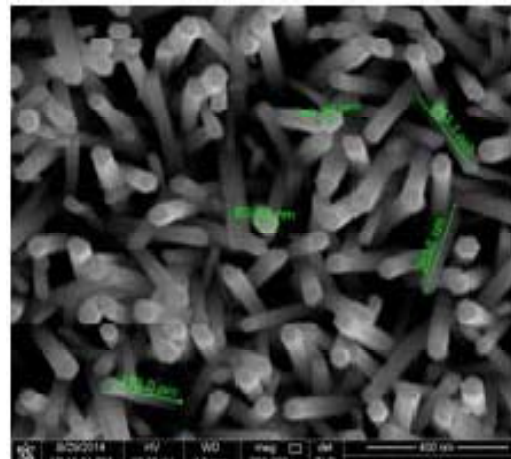

(a)

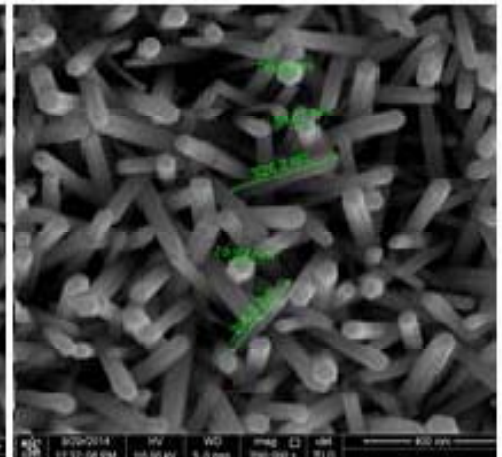

(b)

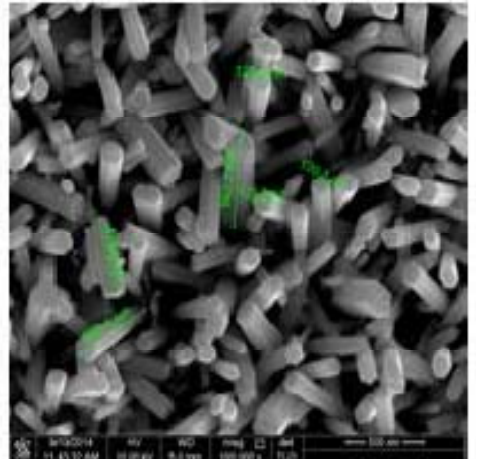

(c)

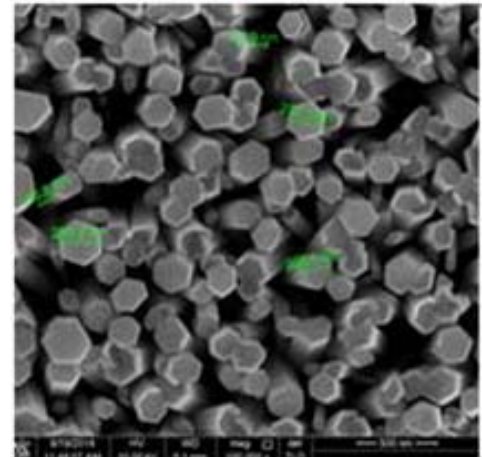

(d)

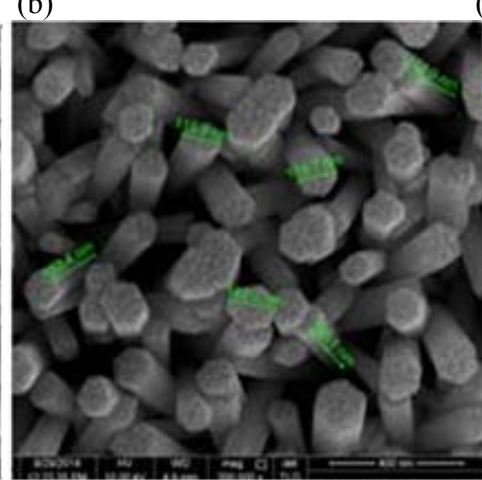

(e)

Fig. 4 Surface FESEM images and diameter of hexagonal ZnO nanorods grown at $90{ }^{\circ} \mathrm{C}$ various concentrations (a) 15 , (b) 20, (c) 25, (d) 30 and (e) $35 \mathrm{mM}$ precursor concentration for $180 \mathrm{~min}$.

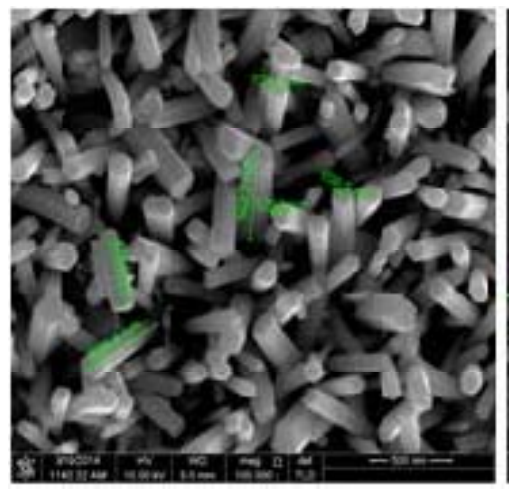

(a)

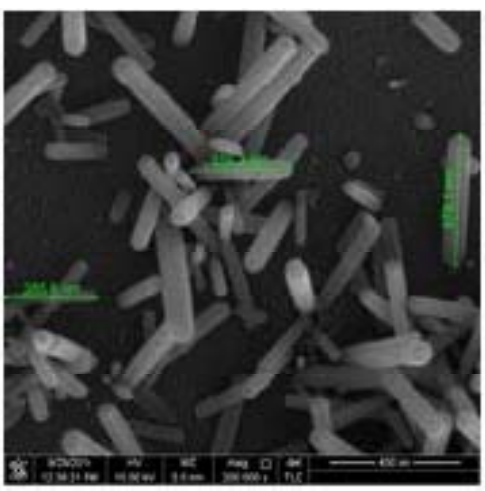

(b)

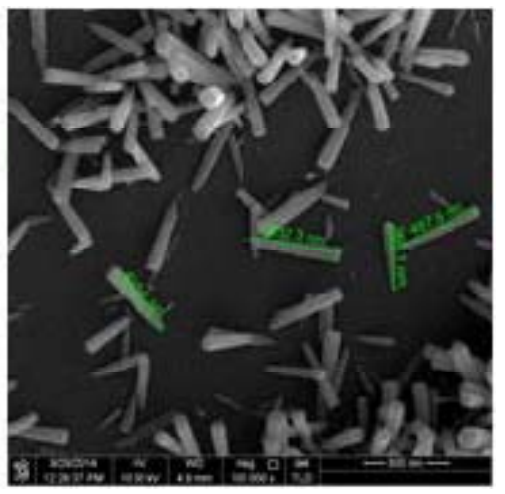

(c)

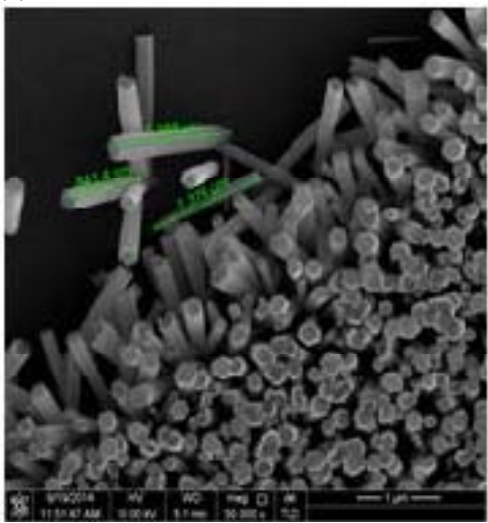

(d)

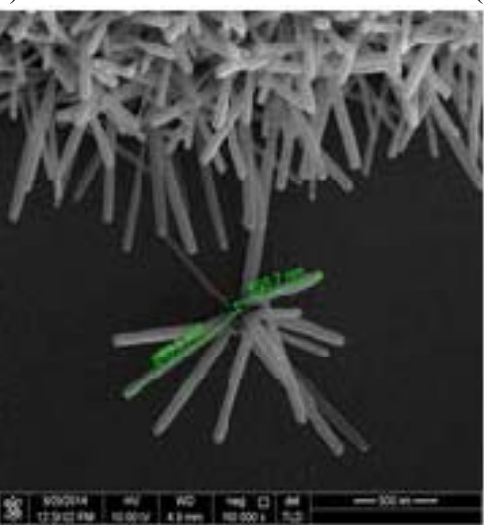

(e)

Fig. 5 Surface FESEM images and length of hexagonal $\mathrm{ZnO}$ nanorods grown at $90{ }^{\circ} \mathrm{C}$ for immersion time (a) 60, (b) 90 , (c) 120, (d) 150 and (e) $180 \mathrm{~min}$ from precursor concentration $35 \mathrm{~mm}$. 
The strain $(\varepsilon \varepsilon)$ of the thin film is determined from the following formula:

$$
\varepsilon=\frac{\beta \cdot \cos \theta}{4}
$$

\subsection{Morphological Analysis of ZnO Nanorods}

In Fig. 4, the FESEM shows the average diameter (d) of the $\mathrm{ZnO}$ nanorods increases from $(57,64,83$, 120 and $230 \mathrm{~nm}$ ) as the precursor concentration increase from 15, 20, 25, 30 and $35 \mathrm{mM}$, respectively, where the immersion time is fixed for $180 \mathrm{~min}$ at $90{ }^{\circ} \mathrm{C}$. The length of the grown $\mathrm{ZnO}$ nanorods is about $1 \mu \mathrm{m}$ regardless of concentration, which indicates that changes in the precursor concentration at the fixed immersion time can affect only the diameter of the hexagonal $\mathrm{ZnO}$ nanorods. The rate of increase diameter of the $\mathrm{ZnO}$ nanorods is estimated to be approximately $34.4 \mathrm{~nm} / \mathrm{mM}$. The length of $\mathrm{ZnO}$ nanorods can also be varied when the immersion time changes in the fixed concentration.

Fig. 5 shows that the average length of the $\mathrm{ZnO}$ nanorods increases from $(241,459,522,820 \mathrm{~nm}$ and $1.2 \mu \mathrm{m})$ as the immersion time $t$ increases from 60,90 , 120, 150 and $180 \mathrm{~min}$, respectively, at the precursor concentration of $35 \mathrm{mM}$. The length of $\mathrm{ZnO}$ nanorods indicates that growth rate is $6.3 \mathrm{~nm} / \mathrm{min}$.

\section{Conclusions}

In this work, we have grown $\mathrm{ZnO}$ nanorods on glass substrates by solution processing hydrothermal method in low temperature using the spin coating technique. The structural, morphological and optical properties were investigated. The hydrothermal method is a relatively simple technique: there are many factors which affected the quality of the film. We have optimized different parameters to obtain a good crystalline structure of $\mathrm{ZnO}$ nanorods with intense and sharp peak. The optical transmittance is over $80 \%$ in the wave length range from $400-800 \mathrm{~nm}$ and the band energy band gap is found to be $3.300 \mathrm{eV}$. According to XRD results, the as deposited films exhibited a hexagonal wurtized structure with (002) preferential orientation after annealing at $400{ }^{\circ} \mathrm{C}$ in air ambiance for $30 \mathrm{~min}$. The XRD pattern consists of a single (002) peak which occurred due to $\mathrm{ZnO}$ crystals and grows along the $c$-axis. The grain size estimated to be $44.46 \mathrm{~nm}$. The average diameter and average length of the $\mathrm{ZnO}$ nanorods obtained from the FESEM. The average diameter of $\mathrm{ZnO}$ nanorods, which are increasing from $(57,64,83,120$ and 230 $\mathrm{nm})$ as the precursor concentration increases at $90{ }^{\circ} \mathrm{C}$ for immersion time $180 \mathrm{~min}$, and the average length of $\mathrm{ZnO}$ nanorods increases from $(241,459,522,820 \mathrm{~nm}$ and $1.2 \mu \mathrm{m}$ ) when the immersion time was increased at $90{ }^{\circ} \mathrm{C}$ for precursor concentration $35 \mathrm{mM}$. The EDX analyses of the samples clearly show that the sample prepared by above route has pure $\mathrm{ZnO}$ nanorod phases.

\section{Acknowledgments}

The authors wish to gratefully acknowledge the financial support from Department of Science \& Technology (Govt. of India), New Delhi as inspire fellow (IF140869) \& library facility provided by National Physical Laboratory (NPL), New Delhi.

\section{References}

[1] Foo, K. L., Hashim, U., Muhammad, K. and Voon, Ch. H. 2014. "Sol-Gel Synthesized Zinc Oxide Nanorods and Their Structural and Optical Investigation for Optoelectronic Application." Nanoscale Research Letters 429: 1-10.

[2] Khan, Z. R., Zulfequar, M. and Khan, M. S. 2010. "Optical and Structural Properties of Thermally Evaporate Cadmium Sulfide Thin Films on Silicon (100) Wafer." Materials Science and Engineering: B 174: 145-9.

[3] Yuan, K., Yin, X., Li, J., Wu, J., Wang, Y. and Huang, F. 2010. "Preparation and DSC application of the Size-Tuned ZnO Nanoarrays." J. Alloy Comp. 489: 694-9.

[4] Caglar, M., Ilican, S. and Caglar, Y. 2009. "Influence of Dopant Concentration on the Optical Properties of $\mathrm{ZnO}$ : In Films by Sol-Gel Method." Thin Solid Films 517: 5023-8.

[5] Heeger, A. J. 2001. "Semiconducting and Metallic 
Polymers: The Fourth Generation of Polymeric Materials." J. Phys. Chem. B 105 (36): 8475.

[6] Xia, Y., Wiesinger, J. M., McDiarmid, A. G. and Epstein, A. J. 1995. "Camphorsulfonic Acid Fully Doped
Polyaniline Emeraldine Salt: Conformations in Different Solvents Studied by an Ultraviolet/Visible/Near-Infrared Spectroscopic Method." Chemistry of Materials 7: 443-5. 